Voix et Images

voixetimages

\title{
Imaginaire Inuit et théâtre pour enfants : l'Umiak
}

\section{Bernard Andrès}

Volume 9, numéro 3, printemps 1984

Monique Bosco

URI : https://id.erudit.org/iderudit/200488ar

DOI : https://doi.org/10.7202/200488ar

Aller au sommaire du numéro

\section{Éditeur(s)}

Université du Québec à Montréal

\section{ISSN}

0318-9201 (imprimé)

1705-933X (numérique)

Découvrir la revue

\section{Citer cet article}

Andrès, B. (1984). Imaginaire Inuit et théâtre pour enfants : l'Umiak. Voix et Images, 9(3), 169-170. https://doi.org/10.7202/200488ar d'utilisation que vous pouvez consulter en ligne.

https://apropos.erudit.org/fr/usagers/politique-dutilisation/ 


\section{THÊÂTRE}

\section{Imaginaire Inuit et théâtre pour enfants: l'Umiak}

par Bernard Andrès, Université du Québec à Montréal

Il s'agit d'un des meilleurs spectacles pour enfants (adolescents et adultes) montés depuis longtemps au Québec. La Marmaille est bien connue depuis dix ans pour son travail auprès des jeunes (et des adultes: on se rappelle la Vie à trois étages, dans le quartier Maisonneuve). À l'origine de sa démarche, l'immersion dans le milieu même qui constituera son sujet et/ou son public. Voilà six ans, l'équipe definissait ainsi ses objectifs:

«Amener le jeune spectateur et/ou le jeune participant à prendre conscience de son potentiel créateur de transformation individuelle et collective. Diffuser auprès des enfants, des animateurs, des professeurs, des parents et des artisans du théâtre, les résultats de nos différentes recherches, afin de faire valoir et de situer l'importance socio-culturelle du premier âge»'.

Entrevues, ateliers d'écriture, de production, tournées jusqu'aux États-Unis et en Angleterre avec On n'est pas des enfants d'école, Pleurer pour rire et l'Umiak, travail d'animation et de recherche en fonction des besoins des milieux défavorisés, etc. Depuis bientôt quatre ans, une nouvelle dimension dans leur champ d'action: le Grand Nord. On sort du milieu somme toute assez douillet des métropoles blanches du sud, pour affronter un autre continent, blanc lui aussi, de neiges et de glaces, mais où les Blancs sont minoritaires. Kuujjuarapik (Poste-de-la-baleine), Inukjuak, Povungnituk, Kangiqsujuak, et d'autres lieux encore qui cachent, sous l'exotisme de leur dénomination, des réalités bien plus prosaïques. La commission scolaire Kativik s'est entendue avec le Ministère des affaires culturelles pour organiser un stage de la Marmaille en milieu inuit. Sur l'expérience ellemême, à l'hiver 82 puis 83 , sur l'écart entre la mission officielle (sensibilisation à l'expression dramatique et valorisation du français auprès de la population autochtone), et les réalités politiques sur le terrain (Convention de la Baie James, conflits ethniques, linguistiques, etc.), on consultera avec profit le dossier de $\mathrm{Jeu} \mathbf{n}^{\circ} 23$. Reste le spectacle né de cette expérience: l'Umiak. 
L'Umiak (le Bateau collectif), c'est d'abord un thêâtre d'environnement et de sensibilisation à la réalité des premiers habitants du pays ${ }^{2}$. En cette année de festivités commémoratives (1534-1984), c'est une dimension qu'on ne saurait oublier. Les gens de la Marmaille y ont été sensibles. Ils ont bâti leur spectacle à partir de leurs contacts dans le village de Salluit avec une quinzaine de stagiaires inuits. Rapidement, la trame du spectacle: la faim assaille le village, la chasse ne donne rien, Luckasi le chasseur se met à rêver: très beau conte sur l'homme et l'aiglon (l'animal posé en adjuvant et conseiller du chasseur); retour et résolution du drame au village. Ce qui séduit dans cette histoire, c'est d'abord la qualité de la dramatisation, de sa mise en espace avec les spectateurs. Un rôle précis est confié à chacun, chacune, devenus enfants, parents ou grands-parents. La salle participe de bon gré. Le public est réparti en trois igloos imaginaires, dans un vaste espace blanc et bleu. On a laissé ses chaussures au vestiaire. Dans le fond une représentation très suggestive de la banquise où le conte sera évoqué. Voix off du Chaman qui raconte, présence du comédien, chasseur et manipulateur de marionnettes. Du poisson salé, des oiseaux, des instruments circulent de mains en mains. On se familiarise avec l'environnement, le décor et la musique (des plus évocatrices, due à Michel Robidoux). Un bandeau de fourrure sur les yeux, on écoute, on sent, on ressent, on imagine plus qu'on n'entend les propos du conteur. Et quand on rouvre les yeux, merveille! Le frère et la soeur de l'aiglon, mi-aigles, mi-humains, se mêlent aux rayures du décor, apparaissent et s'évanouissent, nous entraînent vers d'autres horizons... Nous revoilà près de l'igloo. Sous un immense parachute déployé en corolle, enfants, parents et grands-parents sont invités à imaginer la suite, la fuite, d'autres rêves forgés à même l'histoire vécue.

Face à cette expérience théâtrale des plus réussies, qui s'adresse au jeune public avec toute la fantaisie voulue mais sans niaiserie aucune, on ne peut qu'applaudir. Même si la vision de l'Inuit qui nous est proposée date un peu, fait une place trop belle à l'image rassurante d'un peuple encore heureux, peu touché par l'ambition du sud ou par l'entreprise ethnographique. Pas de blancs à l'horizon. Pas de skidoos, de chèques de pension ni de régie des alcools... Peut-être faut-il d'abord passer par là, par cette image: sensibiliser pour commencer le jeune public à l'existence des premiers occupants. Ensuite, toujours par l'entremise du théâtre, on suscitera peutêtre une vision plus critique du sort effectivement réservé à l'Inuit, ici et maintenant, en ce 450ème anniversaire de l'arrivée de Jacques Cartier. En attendant, bravo pour la Marmaille qui se tourne déjà vers d'autres enfants, ceux du Honduras. À quand l'Arthur Lamothe du théâtre québécois?

1. Cf. Jeu $n^{\circ} 8$ et $n^{\circ} 23$ sur «La Marmaille au Grand Nord».

2. L'Umiak (Le Bateau collectif), création du Thêâtre de la Marmaille: François Camirand, Yves Lauvaux et Monique Rioux. Ecriture: Michel O. Noël. Mise en scène et animation: Monique Rioux. Scénographie: Daniel Castonguay; projections et images: Paul-Emile Rioux; avec François Camirand, Yves Lauvaux et Monique Rioux. Traduction en Inuktitut: Georges Filotas. Au Théâtre d'Aujourd'hui, décembre-janvier 1984. La Marmaille: 849-5469. 